\title{
Placebo use in the context of inflammatory bowel disease clinical trials
}

\author{
Juan Sebastian LASA ${ }^{1,2}$, Ignacio ZUBIAURRE ${ }^{1}$, Astrid RAUSCH ${ }^{1}$ and Pablo OLIVERA ${ }^{2}$
}

Received: 21 August 2019

Accepted: 22 October 2019

\begin{abstract}
Inflammatory bowel disease comprises two distinct conditions - Crohn's disease and ulcerative colitis - which can be treated with immunomodulators. A non-neglectable proportion of these patients will need biologic therapy, and many patients under biologic treatment will experience either primary or secondary failure. As a consequence, clinical trials evaluating new therapeutic alternatives are being developed. These trials share common features, such as being controlled with placebo. Placebo use in clinical trials is a matter of intense debate. Those who support placebo use highlight the methodologic advantages placebo-controlled trials have. Those against placebo use argue that it would be against ethical principles in clinical research to expose a patient to placebo when a valid therapeutic alternative exists. In this review, we summarize the existing arguments for and against the use of placebo in the context of inflammatory bowel disease research. We finally suggest that it is very likely that in the near future inflammatory bowel disease trials will no longer be controlled with a placebo arm, but instead they will be non-inferiority trials with an active comparator.

HEADINGS - Placebos. Inflammatory bowel diseases. Clinical trial.
\end{abstract}

\section{INTRODUCTION}

Inflammatory bowel disease (IBD) comprises a spectrum of immune-mediated disorders that may produce macroscopic lesions throughout the digestive tract, without a known trigger ${ }^{(1)}$. There are two main phenotypes: Crohn's disease (CD) or ulcerative colitis (UC).

These conditions typically present with recurrent relapses, which can lead to persistent lesions located in the colon in the case of $\mathrm{UC}$ or throughout the digestive tract, if $\mathrm{CD}$ is considered ${ }^{(2)}$. As a consequence of such lesions, these patients suffer from recurrent symptoms which can be disabling and require surgical interventions or hospitalization ${ }^{(3)}$.

Since the first descriptions of both UC and CD, their treatment was polarized between surgery and immunosupresive drugs - mainly steroids ${ }^{(4)}$. Surgery carries some non-neglectable risks especially among CD patients, since post-operative relapses are relatively common and a patient may be subject to several interventions with the risk of short bowel syndrome ${ }^{(5)}$. Bearing this in mind, medical treatment became the first alternative for both physicians and patients.

The development of immunomodulators and above all, biologic therapies has redesigned our therapeutic algorithm for $\mathrm{IBD}^{(6)}$. Additionally, since the first clinical trial on Infliximab for $\mathrm{CD}^{(7)}$, an almost unique phenomenon was observed in the field of digestive diseases: a series of randomized, controlled clinical trials were consecutively undertaken, which used similar inclusion and exclusion criteria, same definitions of disease severity and same outcomes.
This feature - which is not seen in clinical trials performed for other GI conditions, such as functional disorders - led to a robust internal and external validity of such clinical trials ${ }^{(8,9)}$, which makes it easier to have a more precise estimation of the effect of such medications in the "real-life" setting.

The vast majority of the aforementioned clinical trials so far has been randomized and controlled with placebo. This implicates that voluntary patients with active disease may be subject to the administration of a drug for a variable period of time and with similar resemblance to the experimental drug but without a known biological effect on their disease's evolution ${ }^{(10)}$.

Placebo use in the context of medical investigation is a matter of debate ${ }^{(11)}$. Until recently, the use of placebo-controlled trials in the field of IBD had been justified by the lack of therapeutic alternatives to treat patients with moderate-to-severe disease and had a steroid-dependent or steroid-refractory condition ${ }^{(12)}$. Nevertheless, in the last two decades there has been an exponential growth in terms of the number of drugs approved for its use in the treatment of both UC and CD: infliximab, adalimumab, certolizumab pegol, golimumab, natalizumab, vedolizumab, tofacitinib, Ustekinumab, to mention some. Moreover, clinical trials on IBD have become more thorough when assessing clinical response: the best example of this is the inclusion of mucosal healing as an outcome in IBD clinical trials ${ }^{(13)}$.

As a consequence, the question that arises is if placebo use in the context of IBD controlled trials is still justified from both ethical and clinical point of view, or if the time has come to change the way clinical trials involving IBD patients are conceived.

Declared conflict of interest of all authors: none

Disclosure of funding: no funding received

Author disclosure statement: Lasa JS: consulting and lecture fees from Sanofi Aventis and Abbvie. Zubiaurre I: consulting and lecture fees from Ferring and Abbvie. Rausch A: lecture fees from Takeda and Abbvie. Olivera P: consulting fees from Abbvie and Takeda, lecture fees from Takeda.

${ }^{1}$ Hospital Británico de Buenos Aires, Gastroenterology Department, Argentina. ${ }^{2}$ CEMIC, Gastroenterology Department, Buenos Aires, Argentina.

Corresponding author: Juan Sebastián Lasa. E-mail: juanselasa@gmail.com 


\section{Why is the use of placebo no longer justified in IBD clinical trials?}

As mentioned before, the use of placebo in the context of controlled trials is a matter of intense debate. Those who advocate for placebo use sustain that placebo-controlled trials are the most practical way to assess the efficacy of an experimental drug. They clearly show an advantage over non-inferiority trials: the need for a lower sample size to demonstrate a biological effect ${ }^{(14)}$. As a consequence, the potential efficacy of a drug could be observed without exposing too many patients to a potentially risky intervention - whether it is the administration of placebo or a non-efficacious drug.

Those who stand against placebo-controlled trial implementation on IBD patients state that is has become unethical, as described in the Declaration of Helsinki ${ }^{(15)}$. According to this document, placebo use in clinical research is justified if no proved therapeutic intervention is available against the condition under investigation. In other words, if an experimental drug would be tested among moderate-to-severe IBD patients who were not previously exposed to all the therapeutic interventions available, then placebo use should be discouraged. The best approach in this case would be a non-inferiority trial comparing the effect of an experimental drug against standard treatment according to what practice guidelines of the condition under study recommend. It constitutes the best approach to minimize the risks and thus protect the integrity of the patient. Most of the clinical trials on IBD that were already published and many of those ongoing include patients who still receive stable doses of aminosalycilates, thiopurines, metrotexate or steroids. However, many of them exclude patients with prior exposure to biologic therapy ${ }^{(16)}$. It is worth mentioning that some clinical trials that contemplate a head-to-head comparison between an experimental drug such as a monoclonal antibody and an anti$\mathrm{TNF} \alpha$ antibody are ongoing ${ }^{(17)}$, an interesting landmark against the use of placebo under these circumstances. In this context, it is worth highlighting that the first head-to-head trial comparing two biologics was recently published - the VARSITY trial ${ }^{(18)}$, which undoubtfully sets a milestone in the history of clinical research in IBD: this is a phase $3 \mathrm{~b}$ randomized, controlled trial was conducted on moderate-to-severe UC patients who had not received biologic therapy which compared two active treatments: vedolizumab and adalimumab.

There are some features that help minimize the risk of placebo exposure which are worth mentioning and should be addressed. One of them is the informed consent ${ }^{(19)}$. Theoretically, a thorough informed consent performed when a voluntary agrees to participate in a clinical trial should include an extensive revision of the potential risks inherent to a potential placebo exposure - even if it only means the lack of symptomatic improvement. Consequently, well-informed patients who still want to participate in a clinical trial are free to do so, assuming the risks of reversible adverse events. This is also debatable, since it is very difficult for a patient to fully understand some medical aspects of clinical trials and thus the whole perspective of their risks and benefits ${ }^{(20)}$.

The Declaration of Helsinki contemplates the use of placebo in the scenario where methodological reasons justify its use, as long as patients are not exposed to irreversible damage. This is probably the point where a plausible justification for placebo use in IBD clinical trials could be found. A position that has been endorsed by some regulatory agencies, such as the European Medicines Agency or the Food and Drug Administration ${ }^{(21)}$. As mentioned before, there are certain theoretical advantages from a methodological point of view when considering placebo-controlled trials. The question would be how the concept of serious or irreversible damage is defined. In the case of IBD patients, if irreversible damage is defined as any clinical circumstance that derives in the need of surgical intervention, then it is very likely that placebo use in the context of a controlled trial does not derive in an increased risk of such damage. On the other hand, most IBD clinical trials enroll patients whose inclusion criteria describe a disease profile that could involve a significant worsening of symptoms as well as repeated hospital admissions, features that from a patient point of view may fall into the category of severe damage. Since patient reported outcomes are increasingly becoming relevant as clinical trial outcomes ${ }^{(22)}$, the severity of potential damage should also take into account what patients feel as severe instead of only the physician's opinion.

Last but not least, it is noticeable that, as time goes by, newer options for IBD treatment with mechanisms of action other than $\mathrm{TNF} \alpha$ antagonism have been developed. By the time SONIC trial ${ }^{(23)}$ was published, only infliximab, adalimumab, certolizumab and natalizumab were approved for IBD treatment by the food and drug administration. Nowadays, selective anti-integrin antibodies such as vedolizumab ${ }^{(24)}$ or interleukin 23 antagonists such as Ustekinumab $^{(25)}$ or JAK2 inhibitors such as tofacitinib ${ }^{(26)}$ have all been approved and marketed for the same purpose. It is expected that in the short term more alternatives will be added to this portfolio which will increasingly cast more doubts on the ethical justification of placebo as control in IBD clinical trials.

\section{Why should placebo still be used in IBD clinical trials?}

Both CD and UC are chronic conditions which are potentially disabling. Biologic therapy has modified the therapeutic perspectives for these diseases; however, despite the advances in terms of diagnosis and treatment, we are far from an ideal situation. For instance, the risk of clinical remission among patients treated with Vedolizumab in the clinical trial setting versus placebo barely reaches $20 \%{ }^{(27)}$. Similar results are observed with the majority of biologics approved so far. Although they represent a notorious advance, improvements are needed.

Another phenomenon that hinders the prognosis of steroiddependent or steroid-refractory IBD patients under biologic treatment is the high rate of both primary and secondary failure that these drugs have shown so far. A relatively high proportion of such patients will receive biologic therapy and will fail to achieve remission (primary failure) ${ }^{(28)}$; among those who show remission with induction treatment, almost $25 \%$ will exhibit a loss of efficacy on the short term (secondary failure) ${ }^{(29)}$. The modification of an anti-TNF $\alpha$ antibody for another (i.e., adalimumab for infliximab) does not decrease the odds of failure and constitutes a risk factor for subsequent failure with further anti- $\mathrm{TNF}^{(30)}$. The aforementioned points highlight the need for the development of new and different drugs targeted to expand the medication options for these patients. Although this may not be the case of other biologics, such as anti-integrin antibodies or anti-interleukin 23 antibodies like vedolizumab or Ustekinumab because of their lower immunogenicity, the response showed to these therapeutic options is 
similar to anti-TNF $\alpha$ antibodies - in addition, prior exposure to a biologic agent seems to behave as a predictor of lower response, irrespective of the type of biologic chosen to rescue patients in that clinical setting ${ }^{(31)}$.

Both CD and UC share the same behavior in time: flares of variable duration and severity that are usually followed by periods of time of symptomatic remission. The moment at which these symptomatic remission periods may occur is still difficult to predict $^{(32)}$. This is not a feature solely observed in IBD patients: other chronic conditions which carry considerable morbidity and even mortality, such as psychiatric disorders ${ }^{(33)}$ show the same fluctuation. This feature becomes a challenge for clinical trials, because their design should be robust enough so that outcomes do not become diluted by the very nature of such conditions. The Declaration of Helsinki, when it addresses the justification of placebo use on clinical trials, highlights that it could be ethically justified should a methodological reason exist ${ }^{(15)}$. Another interesting feature that IBD patients share in the clinical trial setting is their elevated response to placebo. Although it is not a simple task to estimate the actual placebo effect in "the real world" setting, a meta-analysis on the placebo response among UC patients after induction treatment, the global response to placebo was $33 \%$; moreover, this response remains above $30 \%$ when endoscopic outcomes are considered ${ }^{(34)}$. Placebo-controlled trials would hence constitute a solid design from a methodological point of view to minimize the bias inherent to the aforementioned features.

Some considerations should be taken into account regarding the risks that patients are subject to when exposed to placebo instead of an active drug. First of all, in almost every clinical trial involving IBD patients, those with severe disease or a torpid course are excluded. Secondly, the time of risk exposure is of utmost importance ${ }^{(35)}$ : in IBD clinical trials, the response is usually sought within a relatively short period of time. When considering those trials assessing the risk of long-term relapse, enrolled patients have already achieved clinical and/or endoscopic remission. Last but not least, it is worth mentioning that patients participating in clinical trials are subject to a very close and rigorous follow up which can detect in a timely manner those patients who may not be evolving adequately and thus prevent from irreversible damage, as stated by the Declaration of Helsinki.

It is rather difficult to estimate the actual risk of damage that patients who voluntarily participate in clinical trials and receive placebo are exposed to. This has become even more difficult with the addition of patient-reported outcomes ${ }^{(22)}$. However, previous experiences considering placebo-controlled trials could shed some light to this matter. When comparing the incidence of adverse events - serious or not - as well as drop-out rates between patients on placebo arm or active drug arm in previously published antiTNF $\alpha$ trials $^{(16)}$ or anti-integrin antibodies trials ${ }^{(36)}$, no differences are found. What is more, no irreversible damage due to adverse events has been reported in hundreds of patients who have been treated with placebo drugs.

The nature of IBD evolution, the high placebo response rate, the realtively short time of placebo exposure, the lack of prior irreversible damage due to placebo exposure among patients with similar characteristics and the advantages shown from a methodological point of view are reasons to suggest that placebo-controlled trials should still be used in the IBD setting.

\section{Conclusions: is it time for a paradigm change?}

The logic conclusion derived from what has been exposed throughout this manuscript is that there is no definite answer to whether placebo should still be used in IBD clinical trials. This lack of consensus is probably due to the ambiguous statements regarding placebo use observed in ethics practice guidelines. As a consequence, it is very likely that the debate will still continue as long as these guidelines are not reviewed and modified.

These are exciting times in the IBD world: new mollecules as well as monocloncal antibodies targeting other relevant antigens than TNF $\alpha$ are being developed. Additionally, combination therapy using different monoclonal antibodies and/or small mollecules will probably change the perspectives of therapeutic efficacy for IBD, and some scientific breakthroughs regarding IBD genetic background as well as intestinal microbiota's influence on IBD development will undoubtfully modify the way we treat IBD.

Currently, due to regulatory issues supported by the most important agencies in the world such as the FDA or EMA, and also because the valuable information we have gathered throughout the years of research from placebo-controlled trials, it seems that the use of placebo will not be abandoned at present time. Additionally, more emphasis is being put towards safety issues regarding clinical trials in order to prevent any relevant adverse event related to the lack of administration of an effective treatment.

Considering the multiple therapies available nowadays that can be considered as "standard therapies", it is very likely that in the near future IBD clinical trials will no longer be controlled with a placebo arm, but instead will be non-inferiority trials with an active comparator - or at least, placebo-controlled trials will include IBD patients who have failed to every single available approved drug. This will pose a real challenge to pharmaceuticals as well as regulatory agencies.

\section{Authors' contribution}

Lasa JS was involved in the conception of the manuscript as well as writing the draft; Zubiaurre I was involved in the conception of the manuscript as well as bibliographic search and critical review of final draft; Rausch A was involved in bibliographic search and writing the draft; Olivera $\mathrm{P}$ was involved in bibliographic search, writing the draft and critical review of final draft.

\section{Orcid}

Juan Sebastian Lasa. Orcid: 0000-0002-8995-1659.

Ignacio Zubiaurre. Orcid: 0000-0001-8334-9934.

Astrid Rausch. Orcid: 0000-0003-4969-7585.

Pablo Olivera. Orcid: 0000-0002-2740-6102. 
Lasa JS, Zubiaurre I, Rausch A, Olivera P. O uso de placebo no contexto de ensaios clínicos na doença inflamatória intestinal. Arq Gastroenterol. 2020; 57(1):87-90.

RESUMO - A doença inflamatória intestinal compreende duas condições distintas: a doença de Crohn e a retocolite ulcerativa, que podem ser tratadas com imunomoduladores. Uma proporção não negligenciável desses pacientes necessitará de terapia biológica e, muitos destes em tratamento biológico, experimentarão falha primária ou secundária. Como consequência, ensaios clínicos avaliando novas alternativas terapêuticas estão sendo desenvolvidos. Estes ensaios partilham características comuns, tais como ser controlado com placebo. O uso de placebo em ensaios clínicos é uma questão de intenso debate. Aqueles que apoiam o uso do placebo destacam as vantagens metodológicas que os ensaios controlados com placebo têm. Aqueles contra o uso de placebo argumentam que seria contra os princípios éticos na investigação clínica expor um paciente ao placebo quando uma alternativa terapêutica válida existe. Nesta revisão, resumimos os argumentos existentes a favor e contra o uso de placebo no contexto da pesquisa de doença inflamatória intestinal. Finalmente, sugerimos que é muito provável que em um futuro próximo os ensaios de doença inflamatória intestinal não serão mais controlados com um braço placebo; em vez disso, serão feitos ensaios de não-inferioridade com um comparador ativo.

DESCRITORES - Placebos. Doenças inflamatórias intestinais. Ensaio clínico.

\section{REFERENCES}

1. Abraham C, Cho JC. Inflammatory bowel disease. N Engl J Med. 2009;361:2066-78

2. Torres J, Mehandru S, Colombel J-F, Peyrin-Biroulet L. Crohn's disease. Lancet. 2016;2:37-41.

3. Cosnes J, Gower-Rousseau C, Seksik P, Cortot A. Epidemiology and natural history of inflammatory bowel diseases. Gastroenterology. 2011;140:1785-94.

4. Bryant RV, Brain O, Travis SPL. Conventional drug therapy for inflammatory bowel disease. Scand J Gastroenterol. 2015;50:90-112.

5. Sica GS, Biancone L. Surgery for inflammatory bowel disease in the era of laparoscopy. World J Gastroenterol. 2013;19:2445-8.

6. Costa J, Magro F, Caldeira D, Alarcão J, Sousa R, Vaz-Carneiro A. Infliximab Reduces Hospitalizations and Surgery Interventions in Patients With Inflammatory Bowel Disease: A Systematic Review and Meta-analysis. Inflamm Bowel Dis. 2013;19:2098-110.

7. Targan SR, Hanauer SB, van Deventer SJ, Mayer L, Present DH, Braakman T, et al. A short-term study of chimeric monoclonal antibody cA2 to tumor necrosis factor alpha for Crohn's Disease. Crohn's Disease cA2 Study Group. N Engl J Med. 1997;337:1029-35.

8. Rothwell PM. External validity of randomized controlled trials: "To whom do the results of this trial apply?" Lancet. 2005;365:82-93.

9. Zhang X, Wu Y, Ren P Liu X, Kang D. The relationship between external and internal validity of randomized controlled trials: A sample of hypertension trials from China. Contemp Clin Trials Comm. 2015;1:32-38.

10. Gupta U, Verma M. Placebo in clinical trials. Perspect Clin Res. 2013;4:49-52.

11. Millum J, Grady C. The ethics of placebo-controlled trials: methodological justifications. Contemp Clin Trials. 2013;36(2): doi:10.1016/j.cct.2013.09.003.

12. Carter MJ, Lobo AJ, Travis SP. Guidelines for the management of inflammatory bowel disease in adults. Gut. 2004;53(Suppl V):v1-v16.

13. Lichtenstein GR. Importance of mucosal healing in ulcerative colitis. Inflamm Bowel Dis. 2010;16:338-46.

14. Emanuel EJ, Miller FG. The ethics of placebo-controlled trials - a middle ground N Engl J Med. 2001;345:915-9.

15. World Medical Association General Assembly. 2013. Declaration of Helsinki: Ethical principles for medical research involving human subjects. Fortaleza, Brazil. Copyright: World Medical Association. All rights reserved. [Internet]. Available from: https://www.wma.net/policies-post/wma-declaration-pf-helsinki-ethical-principles-for-medical-research-involving-human-subjects

16. Ford AC, Sandborn WJ, Khan KJ, Hanauer SB, Talley NJ, Moayyedi P. Efficacy of biological therapies in inflammatory bowel disease: systematic review and meta-analysis. Am J Gastroenterol. 2011;106:644-59.

17. Gordon JP, McEwan PC, Maguire A, et al. Characterizing unmet medical need and the potential role of new biologic treatment options in patients with ulcerative colitis and Crohn's disease: a systematic review and clinical surveys. Eur J Gastroenterol Hepatol. 2015;27:804-12.

18. Sands BE, Peyrin-Biroulet L, Loftus Jr EV, Danese S, Colombel JF, Törüner M, et al. Vedolizumab versus adalimumab for moderate-to-severe ulcerative colitis. New Engl J Med. 2019;381:1215-26.

19. Temple R, Ellenberg SS. Placebo-controlled trials and active-control trials in the evaluation of new treatments I. Ethical and scientific issues. Ann Intern Med 2000;133:455-63.
20. Nusbaum L, Douglas B, Damus K, Paasche-Orlow M, Estrella-Luna N. Communicating risks and benefits in informed consent for research: a qualitative study. Global Qual Nurs Res. 2017;4:1-13

21. Goodyear MDE, Lemmens T, Sprumont D, Tangwa G. The FDA and the declaration of Helsinki. Br Med J. 2009;338:1157-8.

22. El-Matary W. Patient-reported outcomes measures in inflammatory bowel disease. Can J Gastroenterol Hepatol. 2014;28:536-42.

23. Colombel JF, Sandborn WJ, Reinisch W, Mantzaris GJ, Kornbluth A, Rachmilewitz D, et al. Infliximab, azathioprine, or combination therapy for Crohn's disease. N Engl J Med. 2010;362:1383-95.

24. Feagan BG, Rutgeerts P, Sands BE, Hanauer S, Colombel JF, Sandborn W, et al. Vedolizumab as induction and maintenance therapy for ulcerative colitis. $\mathrm{N}$ Engl J Med. 2013;369:699-710.

25. Feagan BG, Sandborn WJ, Gasink C, Jacobstein D, Lang Y, Friedman JR, et al. Ustekinumab as induction and maintenance therapy for Crohn's disease. N Engl J Med. 2016;375:1946-60.

26. Sandborn WJ, Su C, Panes J. Tofacitinib as induction and maintenance therapy for ulcerative colitis. N Engl J Med. 2017;376:1723-36.

27. Feagan BG, Greenberg GR, Wild G, Fedorak RN, Paré P, McDonald JW, et al. Treatment of active Crohn's disease with MLN0002, a humanized antibody to the alpha4beta7 integrin. Clin Gastroenterol Hepatol. 2008;6:1370-7.

28. Nanda KS, Cheifetz AS, Moss AC. Impact of antibodies to infliximab on clinical outcomes and serum infliximab levels in patients with inflammatory bowel disease (IBD): a meta-analysis. Am J Gastroenterol. 2013;108:40-7.

29. Roda G, Jharap B, Neeraj N, Colombel JF. Loss of response to Anti-TNFs: Definition, epidemiology and management. Clin Transl Gastroenterol. 2016;7, e35; doi:10.1038/ctg.2015.63

30. Dalal SR, Cohen RD. What to do when biologic agents are not working in inflammatory bowel disease patients. Gastroenterol Hepatol. 2015;11:657-65.

31. Liverani E, Scaioli E, Digby RJ, Bellanova M, Belluzzi A. How to predict clinical relapse in inflammatory bowel disease patients. World J Gastroenterol. 2016;22:1017-33.

32. Yanai H, Hanauer SB. Assessing response and loss of response to biological therapies in IBD. Am J Gastroenterol. 2011;106:685-98.

33. Fleischhaker WW, Czobor P, Hummer M, Kemmler G, Kohnen R, Volavka J. Placebo or active control trials of antipsychotic drugs? Arch Gen Psychiatry. 2003;60:458-64.

34. Jairath V, Zou GY, Parker CE, MacDonald JK, AlAmeel T, Al Beshir M. Placebo response and remission rates in randomized trials of induction and maintenance therapy for ulcerative colitis. Cochrane Database Syst Rev. 2017;9: CD011572.

35. Skierka AS, Michels KB. Ethical principles and placebo-controlled trials - interpretation and implementation of the Declaration of Helsinki's placebo paragraph in medical research. BMC Med Ethics 2018;19:24

36. Lasa J, Rausch A, Zubiaurre I. Efficacy and safety of anti-integrin antibodies in inflammatory bowel disease: systematic review and meta-analysis. Acta Gastroenterol Latinoam. 2018;48:106-16.

\section{(c) BY-NC}

